\title{
Estimation of Geoclimatic Factor for Nigeria through Meteorological Data
}

\author{
Ilesanmi B. Oluwafemi and Moses O. Olla
}

\begin{abstract}
Geoclimatic factor variable is one of the most important radio climatic variables in the planning of the radio links in any region. A fade margin that takes into account multipath fading has to be incorporated in the link budget in the design of terrestrial line of sight communication system. This work involves the determination of the refractivity gradient over the first $100 \mathrm{~m}$ above ground level in Nigeria and by using the determined refractivity gradient, the geo-climatic factor $(\mathbf{K})$ was calculated for typical links in Nigeria. The Geo-climatic factor (K) for the six major cities representing each geopolitical zone in Nigeria is determined in-order to improve future planning of the radio links in the regions. Measurement of meteorological parameters for five years taken in Ikeja, Lagos (Latitude $6^{\circ} 27^{\prime} 11^{\prime \prime} N$, Longitude $3^{\circ} 23^{\prime} 44^{\prime \prime} \mathrm{E}$ ), Enugu (Latitude $6^{\circ} 27^{\prime} 35.8704^{\prime \prime} \mathbf{N}$, Longitude $7^{\circ} 32^{\prime} 56.2164^{\prime \prime} \mathrm{E}$ ), Kaduna (Latitude $1^{\circ} 31^{\prime 23}{ }^{\prime \prime} N$, Longitude $7^{\circ} 26^{\prime} 25^{\prime \prime} E$ ), Port Harcourt (Latitude $4^{\circ} 47^{\prime 2} 1^{\prime \prime} \mathrm{N}$, Longitude $6^{\circ} 59^{\prime} 54^{\prime \prime} \mathrm{E}$ ), Kano (Latitude $12^{\circ} 3$ ' N,Longitude $8^{\circ} 32^{\prime} \mathrm{N}$ ) and Abuja (Latitude $9^{\circ} 10^{\prime} 32^{\prime \prime} \mathrm{N}$ Longitude $7^{\circ} 10^{\prime} 50^{\prime \prime} \mathrm{E}$ ) were employed to estimate the country value of $K$. The pressure, $\mathrm{P}(\mathrm{hPa})$, temperature, $\mathrm{T}\left({ }^{\circ} \mathrm{C}\right)$ and the relative humidity, $(\%)$, for the six location used were taken for a period of five years (2011-2015). The value of humidity were converted to water vapour pressure, $\mathrm{e}(\mathrm{hPa})$. In processing of the data, the average values of each month collected over a period of five years was used. The monthly data was used to calculate the values of the refractivity at the ground level and at $100 \mathrm{~m}$ altitude. From the calculated values of refractivity, the values of the refractivity gradient of heights of $65 \mathrm{~m}$ and at $100 \mathrm{~m}$ was computed and thereafter the geo-climatic factor (K) was calculated for the six geopolitical region of the country.
\end{abstract}

Index Terms - Geo-climatic factor, Meteorological data, Microwave, Refractivity, Refractivity Gradient.

\section{INTRODUCTION}

Line-of-sight radio links has a very huge effect on long distance communication networks. Now that there is higher demand for bandwidth that could be supported by recent developments in radio communication technology, reliable and efficient performance of radio link are needed for the transmission of high quality signals. With a wireless medium, the propagation of radio waves between radio link terminals is affected by the troposphere. Whenever there is a poor propagation conditions, fluctuation of the output signal would be resulted to, hence leading to fades on microwave links [1]. This occurrence affects the transmitted signal, and the overall communication system may thus not perform well [2].

Submitted on February 17, 2021.

Published on May 31, 2021.

Ilesanmi B. Oluwafemi, Center for research, Electrical Communication (CRECO), Department of Electrical and Electronic Engineering, Ekiti State University, Ado Ekiti, Nigeria.

(e-mail: ibto75@gmail.com)
Therefore, while designing a highly reliable radio communication network, these fades or signal variations are to be put into consideration [3]. In resolving this deficiency related to radio propagation in different areas of the world, various techniques have been proposed by many authors.

These techniques were developed based on the radio propagation data of the regions in question [4]-[8]. According to those authors, several prediction variables like the geoclimatic factor being the key influence for both the suggestive of geographical and climatic characteristics of the region of interest, is very important [4]. This work involves the determination of the refractivity gradient over the first $100 \mathrm{~m}$ above ground level in Nigeria, using the calculated refractivity gradient, this will then lead to the determination of the geo-climatic factor $(\mathrm{K})$ for typical links in Nigeria.

Tropospheric propagation studies in Nigeria have started for some time. In [1], a study was conducted on the radio refractivity measurement at $150 \mathrm{~m}$ altitude in Akure South West, Nigeria. In [9] the K factor was mapped and refractivity for Calabar in the southeast of Nigeria was calculated while in [10], clear air fade depth due to climatological parameter for microwave links application in Akure Nigeria was estimated. In [11] a study was conducted on the cubic trend line model development for each of the months to predict the refractivity of the lower atmosphere $(<150 \mathrm{~m}$ above sea level $)$ used in predicting multipath fading in terrestrial links. In [12] the inverse distance weighting spatial interpolation technique was used to obtain the missing data at certain height of interest. The results obtained showed that the point refractivity gradient and geo-climatic factor showed monthly and seasonal variations. However, most of the work done so far does not cover the major cities in Nigeria. This paper presents the analysis of the effects of tropospheric factors in the six geopolitical zones in Nigeria to estimate the geoclimatic factor $(\mathrm{K})$.

The rest of the paper is presented as follows. In section II, the overview of the geo-climatic factor is presented while section III presents the findings from the study and finally a conclusion was drawn in section IV.

\section{OVERVIEW OF THE GEOCLIMATIC FACTOR}

The Geo-climatic factor is determined by initially finding other propagation parameters such as refractivity and refractivity gradient [13], [14]. Radio refractivity and its

Moses O. Olla, Center for research, Electrical Communication (CRECO), Department of Electrical and Electronic Engineering, Ekiti State University, Ado Ekiti, Nigeria.

(e-mail: mosesolla83@gmail.com) 
gradient are determined by following the steps recommended by the International Telecommunication Union Radio (ITUR) in recommendation P.453-8 [15], [16]:

$N=(n-1) \times 10^{-6}$

where $N$ is the radio refractivity in $\mathrm{N}$-units, expressed by (ITU2003)

$\mathrm{N}=\frac{77.6}{T}\left(P+4810 \frac{e}{T}\right)$

where $P$ constitutes the total atmospheric pressure in hectorPascal (hPa), $T$ is the absolute temperature (Kelvin), and $e$ is the partial water vapour pressure $(\mathrm{hPa})$ obtained from the relative humidity of air as:

Equation (2) could be used for all radio frequencies, and for frequencies up to $100 \mathrm{GHz}$, with error lesser than $0.5 \%$. As seen in P.453-8, the water vapour, $e$, can be calculated from the relative humidity, $H$, and saturated water vapour $e_{s}$ by these expressions:

$\mathrm{e}=\frac{H e_{S}}{100}$

where $e_{s}$ is expressed by the expression below:

$e_{s}=6.1121 \exp \left(\frac{17.502 t}{t+240.97}\right)$

Combining equations (3) and (4), we get the expression:

$e=H \frac{6.1121 \exp \left(\frac{17.502 t}{t+240,97}\right)}{100}$

Having $H$ as the relative humidity (\%), $T$ as the Celsius temperature $\left({ }^{\circ} \mathrm{C}\right), e_{s}$ is the saturation vapour pressure (hpa) at the temperature $t\left({ }^{\circ} \mathrm{C}\right)$. It has been discovered that the longterm mean dependence of the refractive index $\mathrm{n}$ upon the height $h$ is well expressed as follows [15]:

$n(h)=1+N_{0} \cdot 10^{-6} \exp \left(\frac{-h}{h_{0}}\right)$

where $N_{0}$ is average value of atmospheric refractivity extrapolated to sea level, and $h_{0}$ is the scale height $(\mathrm{km})$. $N_{0}$ and $h_{0}$ can be obtained statistically for different climates. $N_{0}=315$ and $h_{0}=7.35 \mathrm{~km}$ for terrestrial paths [16]. This can be used to calculate the value of refractivity $N_{s}$ at the earth's surface from $N_{0}$ by:

$$
N_{s}=N_{0} \exp \left(\frac{h_{s}}{h_{0}}\right)
$$

Having the $h_{s}=$ height of the earth's surface above the sea level expressed in $(\mathrm{km})$. The radio refractivity gradient $\mathrm{G} \mathrm{N}$ units/km is expressed as (ITU2003):

$\mathrm{G}=\frac{N_{1}-N_{2}}{h_{1}-h_{2}}$

With reference to equation (8), $\mathrm{N} 1$ and $\mathrm{N} 2$ are radio refractivity values at heights $h 1$ and $h 2$ respectively [11]. The proceedings for determining the geo-climatic factor $(\mathrm{K})$ are stated in [10]. In order to calculate $K$, a fairly accurate estimate can be made from the expression [16]:

$K=10^{-4.2-0.0029 d N_{1}}$

where $\mathrm{K}$ is the geo-climatic factor and $\mathrm{d} N_{1}$ is the point refractivity gradient in the lowest $65 \mathrm{~m}$ of the atmosphere not exceeded for $1 \%$ of an average year and can be estimated as follows:

$\mathrm{d} N_{1}=\frac{d N}{d h} \mathrm{I} \mathrm{h} \leq 65 \mathrm{~m}$

\section{RESULT AND DISCUSSION}

The data used in this work was measured in the six geopolitical zones of Nigeria (from January 2010 to December 2014) in six different meteorological stations in the country. The first meteorological station is Kaduna with coordinates (Latitude 10 $31^{\prime} 23^{\prime \prime} \mathrm{N}$, Longitude $7^{\circ} 26^{\prime} 25^{\prime \prime} \mathrm{E}$ ), and elevation $634 \mathrm{~m}$, above the sea level. The second is Enugu station with coordinates (Latitude $6^{\circ} 27^{\prime} 35.8704^{\prime \prime} \mathrm{N}$, Longitude $\left.7^{\circ} 32^{\prime} 56.2164^{\prime \prime} \mathrm{E}\right)$ and elevation $180 \mathrm{~m}$ above the sea level. The third is Abuja with coordinates (Latitude $9^{\circ} 10^{\prime} 32^{\prime \prime} \mathrm{N}$ Longitude $7^{\circ} 10^{\prime} 50^{\prime \prime} \mathrm{E}$ ) with elevation $840 \mathrm{~m}$ above the sea level. The fourth is Kano with coordinates (Latitude $12^{\circ} 3^{\prime} \mathrm{N}$, Longitude $8^{\circ} 32^{\prime} \mathrm{N}$ ) with elevation $488 \mathrm{~m}$ above the sea level and the last is Port Harcourt having coordinates (Latitude 4 $47^{\prime} 21^{\prime \prime} \mathrm{N}$, Longitude 6 $59^{\prime} 54^{\prime \prime} \mathrm{E}$ ) with elevation $20 \mathrm{~m}$ above the sea level.

The parameters extracted are monthly records of pressure, $\mathrm{P}(\mathrm{hPa})$, temperature, $\mathrm{T}\left({ }^{\circ} \mathrm{C}\right)$ and the relative humidity, $(\%)$. The values of humidity were converted to water vapour pressure, e (hPa) by using equation (5) above. In the computation of data, we used the average values for each month collected over the period of five years (2010 to 2014). The monthly data was used to determine the values of surface refractivity at the ground level and at $100 \mathrm{~m}$ altitude using equation (2). From the calculated values of refractivity, we calculated the values of refractivity gradient at heights of $65 \mathrm{~m}$ and $100 \mathrm{~m}$ using equations (8) and (10), respectively. Lastly after finding the $\mathrm{dN}_{1}$, the geo-climatic factor $(\mathrm{K})$ was calculated using equation (9) and the results presented in Fig. 1 to 3 and Table I to II.

The average monthly values of refractivity statistics for each meteorological stations are shown in Fig. 1 and Table I. Table I shows that the average surface refractivity varies with month to month in a year with higher values between May and September for Kano location, higher value for March and December for Abuja, February and October for Enugu, August and September for Kaduna, May and September in Ikeja-Lagos, January, and July for Port Harcourt. It is also seen that the value of surface refractivity is high in Enugu and low in Ikeja-Lagos.

Fig. 2 indicates the monthly variation of point refractivity gradient figures for the six locations viz: Abuja, Enugu, IkejaLagos, Port Harcourt, Kano, and Kaduna. Results showed the worst case is in the raining season between May and November in those years for the six geopolitical zones. 
In order to design the terrestrial line-of-sight systems, a fade margin that takes into account multipath fading has to be integrated into the link budget. The ITU-R (ITU 2015) recommended multipath fading considers frequency of operation, path length, path inclination and the geo-climatic factor of the region of consideration. As showed in [16], the fade margin is directly proportional to the geo-climatic factor. ITU-R suggests that the $\mathrm{K}$ value determined from regional data results in accurate of prediction of multipath fading.

A major item in multipath fade margin determination is the value of $\mathrm{K}$ at the worst month. This corresponds to the month with the highest value of $\mathrm{K}$. Fig. 3 shows the monthly variation of the geo-climatic factor for the six cities employed for the study.

For Kaduna, the months of August and September give a high value of $\mathrm{K}$, with the peak of $\mathrm{K}=0.000899$ in September. In Enugu, the high value of $\mathrm{K}$ takes place in April, May, November, and December with a peak $\mathrm{K}=0.000713$ in May.
For Ikeja Lagos, the high value of $\mathrm{K}$ takes place in January, March, June, and October with a peak K=0.00119 in March. For Abuja, the high value of $\mathrm{K}$ takes place between June and October with a peak $\mathrm{K}=0.000550$ in July. Furthermore, Kano has the high values of $\mathrm{K}$ in January, February, and August with the highest value of $\mathrm{K}=0.000981$ in January. Finally, for Port Harcourt, the high values of $\mathrm{K}$ occur between July and October, with a peak $\mathrm{K}=0.000514$ occurring in July. Thus, Kano exhibits the highest values of $\mathrm{K}$ in the cities considered and is thus most prone to high rates of multipath fading. Note that for Akure Southwest Nigeria, the highest value of $\mathrm{K}=0.00092$ occurred in October and the lowest value of 0.000132 occurred in December [10]. The average value of $\mathrm{K}$ for Akure is 0.000327 , which is comparable to the average values for Abuja, Kaduna, Ikeja, Port Harcourt, Enugu and Kano which is $0.000214,0.000245,0.000446$, $0.000239,0.000297$ and 0.000319 , respectively.

TABLE I: AVERAGE MONTHLY VALUES OF REFRACTIVITY

\begin{tabular}{crccccc}
\hline Calendar & \multicolumn{5}{c}{ Refractivity, N-units } \\
\cline { 2 - 6 } Months & Kano & Abuja & Enugu & Kaduna & Lagos & Port Harcourt \\
\hline Jan & 28.033 & 140.837 & 95.343 & 24.893 & 43.273 & 107.182 \\
Feb & 39.888 & 153.653 & 116.652 & 39.599 & 34.022 & 110.881 \\
Mar & 20.034 & 112.871 & 196.265 & 37.866 & 35.066 & 119.301 \\
Apr & 57.723 & 126.276 & 175.575 & 76.649 & 38.508 & 117.088 \\
May & 82.861 & 127.525 & 192.945 & 89.413 & 47.944 & 113.181 \\
Jun & 85.392 & 126.131 & 194.683 & 86.523 & 44.201 & 113.120 \\
Jul & 68.836 & 125.437 & 192.429 & 82.398 & 48.715 & 113.085 \\
Aug & 91.787 & 141.471 & 206.246 & 106.913 & 41.461 & 96.981 \\
Sep & 91.929 & 116.036 & 209.539 & 103.015 & 44.366 & 91.274 \\
Oct & 67.015 & 135.586 & 206.378 & 70.789 & 38.811 & 111.181 \\
Nov & 42.707 & 150.609 & 184.841 & 29.057 & 37.933 & 112.060 \\
Dec & 28.374 & 167.538 & 89.515 & 40.681 & 28.149 & 107.147 \\
\hline
\end{tabular}

TABLE II: GEO-CLIMATIC FACTOR (K) FOR DifFERENT MONTHS FOR KADUNA, ENUGU, LAGOS, ABUJA, KANO AND PORT HARCOURT

\begin{tabular}{|c|c|c|c|c|c|c|}
\hline \multirow{2}{*}{$\begin{array}{l}\text { Calendar } \\
\text { Months }\end{array}$} & \multicolumn{6}{|c|}{ Geo-climatic Factor, K } \\
\hline & Kaduna & Enugu & Lagos & Abuja & Kano & Port Harcourt \\
\hline Jan & 0.0000522 & 0.000138 & 0.000710 & 0.0000837 & 0.000981 & 0.0000838 \\
\hline Feb & 0.000240 & 0.000280 & 0.000298 & 0.0000647 & 0.000744 & 0.0000562 \\
\hline Mar & 0.0000483 & 0.000363 & 0.00119 & 0.0000495 & 0.000102 & 0.0000672 \\
\hline Apr & 0.000167 & 0.000551 & 0.000144 & 0.000147 & 0.000256 & 0.0000139 \\
\hline May & 0.000124 & 0.000713 & 0.000222 & 0.000202 & 0.0000933 & 0.0000158 \\
\hline Jun & 0.0000752 & 0.000134 & 0.000904 & 0.000298 & 0.000156 & 0.000319 \\
\hline Jul & 0.000229 & 0.000264 & 0.0000922 & 0.000550 & 0.000282 & 0.000514 \\
\hline Aug & 0.000899 & 0.000158 & 0.000222 & 0.000298 & 0.000362 & 0.000481 \\
\hline Sep & 0.000893 & 0.000138 & 0.000342 & 0.000363 & 0.00126 & 0.000340 \\
\hline Oct & 0.0000863 & 0.000155 & 0.000827 & 0.000264 & 0.000154 & 0.000434 \\
\hline Nov & 0.0000618 & 0.000615 & 0.000226 & 0.000110 & 0.000166 & 0.000138 \\
\hline Dec & 0.0000636 & 0.000588 & 0.000172 & 0.000141 & 0.000139 & 0.000138 \\
\hline Average & 0.000245 & 0.000297 & 0.000446 & 0.000214 & 0.000319 & 0.000239 \\
\hline
\end{tabular}



Fig. 1. Average monthly variation of refractivity in Kano, Abuja, Enugu, Kaduna, Ikeja and Port-Harcourt.

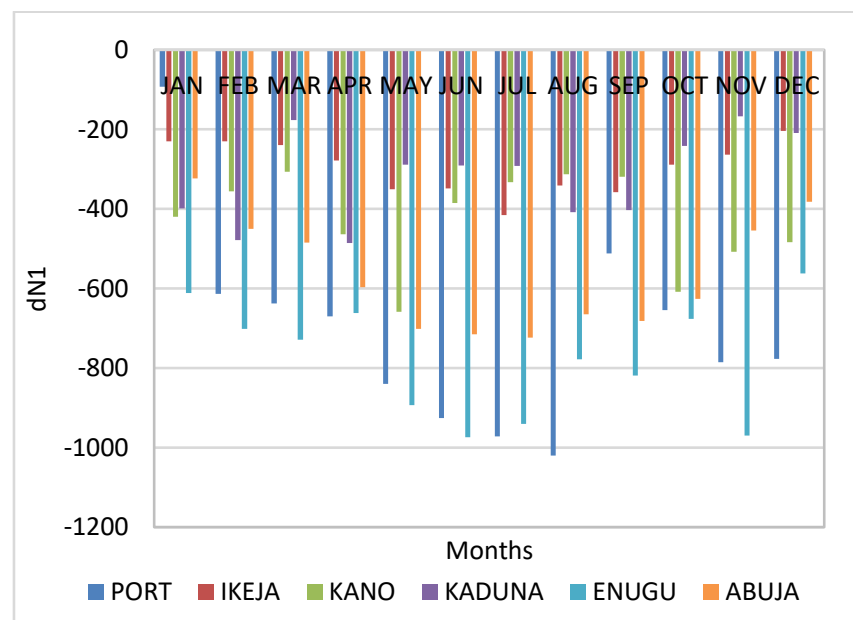

Fig. 2. Point refractivity gradient for Port-Harcourt, Ikeja, Kano, Kaduna, Enugu, and Abuja 


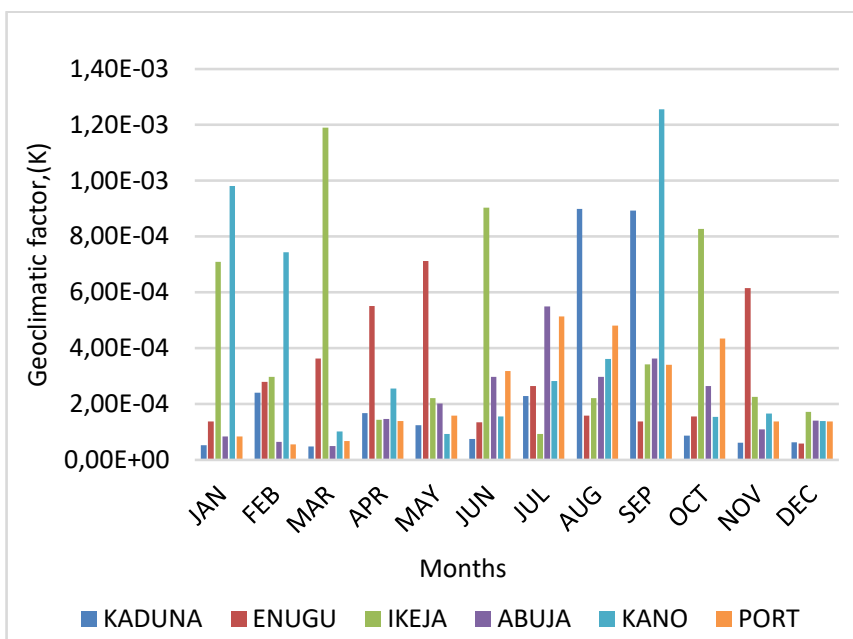

Fig. 3. Geo-climatic factor (K) variation for Kaduna, Enugu, Ikeja, Abuja, Kano, and Port-Harcourt.

\section{CONCLUSION}

In this paper, the Geo-climatic factor $(\mathrm{K})$ variable, which is one of the most important radio climatic variables in the planning of the radio links in the region, has been calculated for Abuja, Kaduna, Ikeja, Port Harcourt, Enugu, and Kano in the six geopolitical zones in Nigeria. It is observed that as the values of $\mathrm{dN} 1$ become more negative, the Geo-climatic factor increases. The average of the geo-climatic factor is 0.000245 for Kaduna, 0.000297 for Enugu, 0.000446 for Ikeja, 0.000214 for Abuja, 0.000319 for Kano and 0.000239 for Port Harcourt. The worst month values of $\mathrm{K}$ are determined to be 0.000889 for Kaduna in August, 0.000615 for Enugu in November, 0.000827 for Ikeja in October, 0.000550 for Abuja in July, 0.000981 for Kano in January and a high value of 0.000514 for Port Harcourt in July.

\section{REFERENCES}

[1] Adediji A.T., Ajewole M.O., Falodun S.E. and Oladosu O.R. (2007). "Radio Refractivity Measurement at $150 \mathrm{~m}$ altitude on TV tower in Akure, South-West Nigeria" Journal of Engineering and Applied Science, 2007, Nigeria.

[2] Willis, M. Bacon, D, Craig, K. and Rudd R. (2000) "A wide Range Propagation Model,” IEEE Conferences, 2000, pp.1-5.

[3] Yu S. M., Yee Hui L. and Boon C. N. (2009) "Empirical Near Ground Path Loss Modeling in a Forest at VHF and UHF Bands," IEEE Journals, vol.57, no. 5, pp.1461-1468.

[4] Odedina P.K. and Afullo T.J. (2007), "Use of Spatial Interpolation Technique for the Determination of the Geoclimatic Factor and Fade Depth Calculation for Southern Africa," Proceedings of IEEE AFRICON conference 2007 ISBN: $0-7803-8606-X$. IEEE Catalogue number: 04CH37590C, September 26 - 28, 2007, Namibia.

[5] Tjelta T., Oslen R.L. and Martin A.L. (1990), "Systematic Development of New Multivariable Techniques for Predicting the Distribution of Multipath Fading on Terrestrial Microwave Link," IEEE Transaction on antennas and Propagation, vol.38, pp. 1650-1665.

[6] Olsen R. L. and Tjelta T. (1999), "Worldwide Techniques for predicting the Multipath Fading Distribution on Terrestrial L.O.S. Links: Background gation, Vol. 47, January 1999, pp. 157-170.

[7] Olsen R. L. and Segal B. (1992), "New techniques for predicting the Multipath Fading Distribution on VHF/ UHF/SHF Terrestrial Line-ofSight Links in Canada Canada Journal of Elec. And Comp. Engineering, Vol. 17, No 1., pp. 11-23.

[8] Martin A., "Key Radio Meteriological Parameters for Designing Line of Sight Links in Multipath Fading Environment," Martin Communications Pty Ltd, 87 Peters Av, Mulgrave VIC 3170, Australia.

[9] Ezenugu I. A., Ifiok U. Anthony O.and Colman O. A. (2017), "Estimation of Clear-Air Atmospheric Effective Earth Radius (K-

Factor) in Calabar". American Journal of Software Engineering and Applications. vol. 2, No. 3, pp. 35-37, 2017.

[10] Ojo O. L., Ajewole M. O., Adediji A.T. and Ojo J. S. (2015) "Estimation of Clear-Air Fades Depth Due to Radio Climatological Parameters for Microwaves Link Application in Akure, Nigeria". International Journal of Engineering and Applied Sciences, August 2015. Vol. 7. No. 03.

[11] Rosemary N. C., Simeon O. and Colman O. A. (2017). "Vertical Radio Refractivity Profile for Calabar in the Southern Region of Nigeria". Engineering Physics. vol. 2, No.1, 2017, pp. 1-6.

[12] Etokebe I. J., Uko M. C., and Chinwe I. U. (2016), "Determination of Refractivity Gradient and Geoclimatic Factor Using Radiosonde Data and Inverse Distance Weighting Spatial Interpolation for Missing Data". International Journal of Systems.

[13] Dabideen A.S., Gopichund M., and Afullo T.J. (2005), "Radio Refractivity Distribution and Duct and Fading Occurrence Measurements in Kwazulu-Natal" Transactions of South African Institute of Electrical Engineers (SAIEE), Volume 96, No.2, June 2005 , pp121-132.

[14] Valma E., Tmosiunarte M., Tamosiunas S. and Zilinkas M. (2011), "Variation of Radio refractivity with height above ground" Electrical and Electronics Engineering, 2011 No 5(111).

[15] ITU Radio communication Assembly (2015), "Prediction Methods Required for the Design of Terrestrial Line of Sight -R P. 530 16; July 2015.

[16] ITU Radio communication Study Group III (2003): “The Radio Refractive Index: Its formula and Refractivity Data" ITU Radio communication Assembly Document No. ITU-R P.453 -7, 11 July 2003.

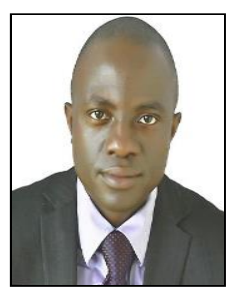

Ilesanmi B. Oluwafemi received the B. Eng degree in Electrical and Electronic Engineering from University of Ado Ekiti, Nigeria in 2000. He obtained the Master of Engineering degree in Electronic and Telecommunication from University of Benin, Nigeria in 2005 and PhD in Electronic Engineering from the University of KwaZulu-Natal, Durban, South Africa in 2012. He is currently a Senior Lecturer and the Head of Department of Electrical and Electronic Engineering, Ekiti State University, Nigeria. He is also the Leader of the Center for Research in Electrical Communication (CRECO), Ekiti State University, Ado-Ekiti, Nigeria. His research interests are in the area of wireless communication including space-time coding, channel coding, MIMO and OFDM systems and signal propagation.

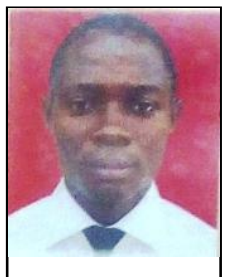

propagation
Moses O. Olla received the B. Eng degree in Electrical and Electronic Engineering from Ekiti State Ado Ekiti, Nigeria in 2016. He obtained the Master of Engineering degree in Electronic and Telecommunication from the same University, in 2019.He is currently studying towards the degree of $\mathrm{PhD}$ in Electronic Engineering in Federal University of Oye Ekiti, Nigeria. His research interests are in the area of wireless communication including microwave propagation and signal 